\title{
NO and ABA Interaction Regulates Tuber Dormancy and Sprouting in Potato
}

\author{
Zhike Wang ${ }^{1}$, Rui Ma ${ }^{2,3,4}$, Mengshi Zhao ${ }^{1}$, Fangfang Wang ${ }^{1}$, Ning Zhang ${ }^{1 *}$ and \\ Huanjun Si ${ }^{1,2}$ \\ ${ }^{1}$ College of Life Science and Technology, Gansu Agricultural University, Lanzhou, China, ${ }^{2}$ Gansu Provincial Key Laboratory \\ of Aridland Crop Science, Gansu Agricultural University, Lanzhou, China, ${ }^{3}$ College of Agronomy, Gansu Agricultural \\ University, Lanzhou, China, ${ }^{4}$ Dingxi Academy of Agricultural Sciences, Dingxi, China
}

\section{OPEN ACCESS}

Edited by:

Juan Carlos Begara-Morales,

University of Jaén, Spain

Reviewed by:

Leon A. Terry,

Cranfield University, United Kingdom Michael Campbell, Penn State Erie, The Behrend

College, United States

*Correspondence:

Ning Zhang

ningzh@gsau.edu.cn

Specialty section: This article was submitted to Plant Physiology,

a section of the journal

Frontiers in Plant Science

Received: 22 October 2019

Accepted: 03 March 2020

Published: 08 April 2020

Citation:

Wang Z, Ma R, Zhao M, Wang F,

Zhang $N$ and Si H (2020) NO and ABA Interaction Regulates Tuber

Dormancy and Sprouting in Potato.

Front. Plant Sci. 11:311.

doi: 10.3389/fp/s.2020.00311
In plants, nitric oxide synthase (NOS)-like or nitrate reductase (NR) produces nitric oxide (NO), which is involved in releasing seed dormancy. However, its mechanism of effect in potato remains unclear. In this study, spraying $40 \mu \mathrm{M}$ sodium nitroprusside (SNP), an exogenous NO donor, quickly broke tuber dormancy and efficiently promoted tuber sprouting, whereas 2-(4-carboxyphenyl)-4,4,5,5-tetramethylimidazoline-1-oxyl-3oxide (c-PTIO), an NO scavenger, repressed the influence of $\mathrm{NO}$ on tuber sprouting. Compared with the control (distilled water), SNP treatment led to a rapid increase in NO content after $6 \mathrm{~h}$ and a decreased abscisic acid (ABA) content at 12 and $24 \mathrm{~h}$. c-PTIO treatment significantly inhibited increase of $\mathrm{NO}$ levels and increased ABA production. In addition, $N^{G}$-nitro-L-arginine methyl ester, an NOS inhibitor, clearly inhibited the NOS-like activity, whereas tungstate, an NR inhibitor, inhibited the NR activity. Furthermore, NO promoted the expression of a gene involved in ABA catabolism (StCYP707A1, encoding ABA 8'-hydroxylase) and inhibited the expression of a gene involved in ABA biosynthesis (StNCED1, encoding 9-cis-epoxycarotenoid dioxygenase), thereby decreasing the ABA content, disrupting the balance between $A B A$ and gibberellin acid (GA), and ultimately inducing dormancy release and tuber sprouting. The results demonstrated that NOSlike or NR-generated NO controlled potato tuber dormancy release and sprouting via ABA metabolism and signaling in tuber buds.

Keywords: nitric oxide, potato, tuber dormancy, sprouting, NO synthase, abscisic acid, nitrate reductase

\section{INTRODUCTION}

The potato (Solanum tuberosum L.) is an important food crop and industrial raw material. Plant dormancy and subsequent germination are physiological processes of active adaptation to the environment. Potato tuber dormancy is defined as an inability to sprout under conditions that are favorable for sprouting (Liu et al., 2015). The dormancy and sprouting of potato tubers are very significant for potato cultivation, tuber production, and industrial processing (Aksenova et al., 2013). In potato cultivation, the dormancy degree of tubers as seed potatoes affects the emergence of seedlings in the field, uniformity, and yield (Sonnewald and Sonnewald, 2014), especially in the two season-cropping areas; excessive dormancy will prolong the sprouting and growth of tubers and finally affects the increase of yield. When tubers are used as food or raw materials for processing, 
a long dormancy period is essential for transportation and storage, and dormancy release results in a large consumption of water and nutrients, decreasing commodity quality and value (Aksenova et al., 2013). Potato tubers exhibit a certain dormancy period after maturation, which ends with the occurrence of buds. The release of dormancy was essential for the sprouting of tubers, which was regulated by both internal and external factors (Koornneef et al., 2002). Tuber dormancy was also regulated by a variety of factors and was dependent on plant hormones (Suttle et al., 2012; Sonnewald and Sonnewald, 2014), genetic factors, tuber variety, storage temperature and conditions, and particular signaling molecules, such as nitric oxide (NO) (Noritake et al., 1996) and reactive oxygen species (ROS) (Peivastegan et al., 2019). In many plants, the balance between abscisic acid (ABA) and gibberellin acid (GA) is a major regulator of the dormancy state, in which GA promotes the progression from breaking to sprouting (Wróbel et al., 2017).

$\mathrm{NO}$ is a gaseous free radical that can easily diffuse through biofilms. NO plays a role in numerous plant physiological processes (Begara-Morales et al., 2019), such as transport (Sun et al., 2018), germination (Liu et al., 2010; Arc et al., 2013a), flowering (Khurana et al., 2011), metabolism (Hasanuzzaman et al., 2018), and senescence (Sun, 2018). Moreover, NO is a significant signaling molecule that regulates the plant response to various nonbiological and biological stresses (Begara-Morales et al., 2018), such as stomatal closure (Zhang et al., 2019), heat stress (Parankusam et al., 2017), disease (Srinivas et al., 2014), drought (Wang et al., 2016), and programmed cell death (Ma et al., 2010). Exogenous NO treatment was reported to break dormancy and promote germination in seeds of three warmseasons $\mathrm{C}_{4}$ grasses (Sarath et al., 2006).

In mammals, NO synthase (NOS) is the key enzyme that produces NO (Parankusam et al., 2017). There are numerous potential sources of $\mathrm{NO}$ in plants, which are predominantly mediated by NOS and nitrate reductase (NR) (ChamizoAmpudia et al., 2017). In the presence of NADPH as an electron donor, NOS catalyzes the conversion of L-arginine to L-citrulline and NO (Stuehr et al., 2004), whereas NR reduces nitrates to NO (Gupta et al., 2011). Although the occurrence of NOS in plants has not yet been definitively demonstrated, some studies have indicated that NOS-like activities existed in many plants (Parankusam et al., 2017). These NOS-like activities appeared to be somewhat similar to mammalian NOS (Del Río et al., 2004). Moreover, $\mathrm{N}^{G}$ nitro-L-arginine methyl ester (L-NAME), an NOS inhibitor, inhibited NO synthesis in plants (Zhang et al., 2007). In addition, tungstate, an NR inhibitor, inhibited NO synthesis in Arabidopsis (Kolbert et al., 2010).

Sodium nitroprusside (SNP) is an NO donor that induces the production of NO. Exogenous SNP treatment was reported to break dormancy of barley (Bethke et al., 2004). 2-(4carboxyphenyl)-4,4,5,5-tetramethylimidazoline-1-oxyl-3-oxide (c-PTIO) is an NO scavenger that blocks the effects of NO donors and prolongs the dormancy in Arabidopsis (Liu et al., 2009). Some researchers have demonstrated interaction between NO signal transduction and ABA (Zhang et al., 2007; Arc et al., 2013a). For example, NO was involved in stomatal closure induced by ABA (Zhang et al., 2019). However, the crosstalk between $\mathrm{NO}$ and $\mathrm{ABA}$ in potato tuber dormancy and sprouting currently remains unclear. Therefore, this study focused on the influence of NO on potato tuber sprouting and investigated the relationship between ABA metabolism and NO signaling in tuber buds and the roles of NOS-like and NR in tuber sprouting.

\section{MATERIALS AND METHODS}

\section{Plant Materials}

The potato (S. tuberosum L.) cultivar "Favorita" was used in the study. The potatoes were planted in Dingxi Academy of Agricultural Sciences, Dingxi City, Gansu Province, China. The harvested tubers were stored at room temperature $\left(25^{\circ} \mathrm{C} \pm 1^{\circ} \mathrm{C}\right)$ (approximately 90\% humidity) in the dark until fully mature. According to report, it takes approximately 1 week for harvested tubers to reach full maturity. When tubers mature completely, cell division is mainly concentrated in the epidermis and periderm cells. The inner cells of the tuber mainly accumulate and develop starch grains. The cell volume typically stops expanding, and few cells divide, whereas starch accumulation is very rich. The degree of vacuolation of cells continues to decrease and is becoming dormant (Teper-Bamnolker et al., 2012). SNP, L-NAME, tungstate, ABA, and c-PTIO were obtained from Beijing Biomarker Technology Company (Beijing, China).

\section{Tuber Sprouting Test}

Healthy tubers with similar size (70-80 $\mathrm{mm}$ in diameter) were selected. Dormant tubers were sprayed with distilled water (DW; control) or $10,20,40,80,160$, or $320 \mu \mathrm{M}$ SNP for $15 \mathrm{~min}$. There were three repetitions per treatment and 50 tubers per repetition. The treated tubers were placed in a box and stored in a cool and well-ventilated place. The sprouting rate was counted every 10 days to determine the optimal SNP concentration. The tuber sprouting rate $(\%)=$ (sprouted tuber number/tuber total $\times 100$. The sprouted tuber means that the first bud of the tuber reaches $2 \mathrm{~mm}$ as the sprouting standard (Abbasi et al., 2015). This SNP concentration was then used in the subsequent combination assay, in which dormant tubers were sprayed with either DW (control), $40 \mu \mathrm{M}$ SNP, $1 \mathrm{mM} \mathrm{c-PTIO,} \mathrm{or} 40 \mu \mathrm{M}$ $\mathrm{SNP}+1 \mathrm{mM} \mathrm{c}$-PTIO for $15 \mathrm{~min}$. To investigate whether NO improves the tolerance to $\mathrm{ABA}$, dormant tubers were sprayed with either DW (control), $100 \mu \mathrm{M}$ ABA, $100 \mu \mathrm{M} \mathrm{ABA}+40 \mu \mathrm{M}$ $\mathrm{SNP}$, or $100 \mu \mathrm{M} \mathrm{ABA}+1 \mathrm{mM} \mathrm{c}$-PTIO for $15 \mathrm{~min}$. The bud eye tissues were sampled at $0,10,20,30,40,50$, and 60 days (Liu et al., 2015).

\section{Determination of NO and ABA Contents}

The NO content was measured using an enzyme-linked immunosorbent assay (ELISA) kit (Wuhan Purity and Biotechnology Co., Ltd., Wuhan, China) according to the manufacturer's instructions. The ABA content was measured using an ELISA kit (Shanghai Jianglai Biotechnology Co., Ltd., 
Shanghai, China) according to the manufacturer's instructions, as described by Zhang et al. (2009).

\section{Determination of NOS-Like and NR Activities}

NOS-like activity was measured using a plant NOS ELISA Kit (Shanghai Xinyu Biotechnology Co., Ltd., Shanghai, China) according to the manufacturer's instructions, as described by Diao et al. (2017). The NR activity was measured as described by Lu et al. (2014). Approximately $1.0 \mathrm{~g}$ of tuber bud eye tissues were ground in a mortar, and $10 \mathrm{~mL}$ of $50 \mathrm{mM}$ phosphate buffer ( $\mathrm{pH}$ 7.8) was added. The homogenate was centrifuged at 12,000 revolutions $/ \mathrm{min}$ for $20 \mathrm{~min}$. The supernatant was transferred to a new centrifuge tube, and the nitrite production was determined by measuring the absorbance at $540 \mathrm{~nm}$ using an ultraviolet-visible spectrophotometer.

\section{RNA Extraction, Reverse Transcriptase-Polymerase Chain Reaction, and Quantitative Reverse Transcriptase-Polymerase Chain Reaction}

Fresh samples of RNA were extracted at various time points. The total RNA was isolated using an Easy Pure Plant RNA Kit (Quanshijin, Beijing, China). The extracted RNA was immediately stored at $-80^{\circ} \mathrm{C}$. RNA samples with an $\mathrm{OD}_{260} / \mathrm{OD}_{280}$ ratio of between 1.98 and 2.0 were used in subsequent experiments. cDNA synthesis was performed using a TransScript One-Step gDNA Removal and cDNA Synthesis Super MixKit (Quanshijin). The cDNA solution was diluted eightfold with nuclease-free water. TransStart Green qPCR SuperMix (Quanshijin) was used to analyze the expression of key genes involved in potato dormancy release. Quantitative reverse transcriptase-polymerase chain reaction (qRT-PCR) was performed using a Light Cycler 96 real-time PCR system (Roche, Basel, Switzerland) in a total reaction volume of $20 \mu \mathrm{L}$ containing $10 \mu \mathrm{L} 2 \times$ TransStart Green qPCR SuperMix, $1.0 \mu \mathrm{L}$ each primer $(10 \mu \mathrm{mol} / \mu \mathrm{L}), 2.0 \mu \mathrm{L} \mathrm{cDNA}$, and $6.0 \mu \mathrm{L}$ double-distilled water. The reactions were mixed gently and incubated at $95^{\circ} \mathrm{C}$ for $15 \mathrm{~min}$, followed by 40 cycles of $95^{\circ} \mathrm{C}$ for $30 \mathrm{~s}, 62^{\circ} \mathrm{C}$ for 45 $\mathrm{s}$, and $72^{\circ} \mathrm{C}$ for $60 \mathrm{~s}$. The qRT-PCR primer sequences were as follows: StNOS-IP (F5'-ACTTGTCCTGAAGGGAGGGA-3'; R5'-AGACCACGCAAACCTTGTCA-3'), StNR (F5'-AACGC TGAAGCATGGTGGTA-3'; R5 $^{\prime}$-CACCTCAACCTCGAGTGA CC-3'), StEF1 $\alpha$ (F5'-CAAGGATGACCCAGCCAAG-3'; R5' -TT CCTTACCTGAACGCCTGT-3'), StCYP707A1 (F5'-CAGGC TTTCAAGCCCGATTC- $3^{\prime}$; R5'-TGAAGAGTGTACCGTGG AGA-3'), StNCED1 (F5'-ACAGCCGGACACCATTTCTT-3'; R5'-CTAAACCGGCGTTTGCAACT-3'). The potato StEF1 $\alpha$ gene was used as an internal reference gene. The $2^{-\Delta \Delta C t}$ method was used to calculate the relative expression level of target genes (Livak and Schmittgen, 2001). All samples were carried out with three biological replicates and three technical replicates (Kundu et al., 2013).

\section{Statistical Analysis}

The data were analyzed using the IBM SPSS Statistics 20 software package (Amonk, New York). The different treatments were compared using Duncan multiple-range test with a significance level of $p<0.05$. The charts were prepared using GraphPad Prism 8 (San Diego, United States).

\section{RESULTS}

\section{Effects of SNP and c-PTIO on Tuber Sprouting}

Spraying potato tubers with various concentrations of SNP led to sprouting rates of $71.18 \%(10 \mu \mathrm{M}), 86.55 \%(20 \mu \mathrm{M}), 93.54 \%$ $(40 \mu \mathrm{M}), 67.17 \%(80 \mu \mathrm{M}), 56.12 \%(160 \mu \mathrm{M}), 44.60 \%(320 \mu \mathrm{M})$, and $72.61 \%$ (control) at 60 days after treatment (Figure 1A). In the combination experiment, the tubers sprayed with $40 \mu \mathrm{M}$ SNP had a sprouting rate of $56.23 \%$ at 20 days after treatment, whereas the c-PTIO-treated tubers had a sprouting rate of $3.04 \%$, and the control group sprayed with DW had a sprouting rate of

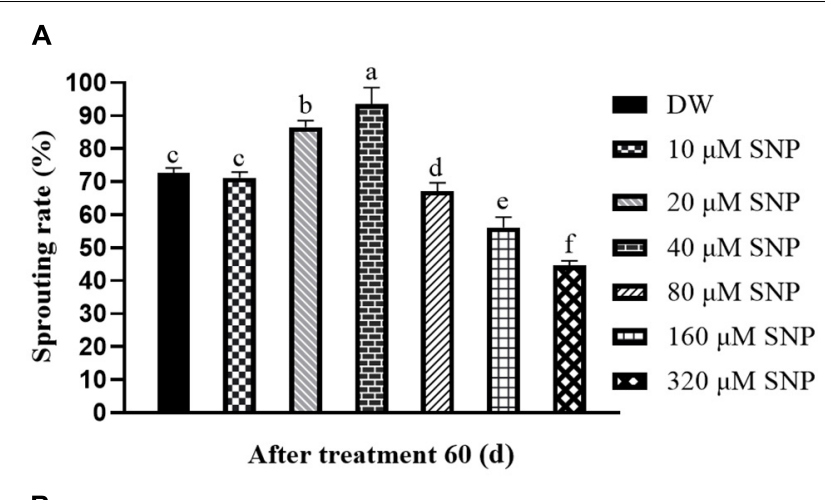

B

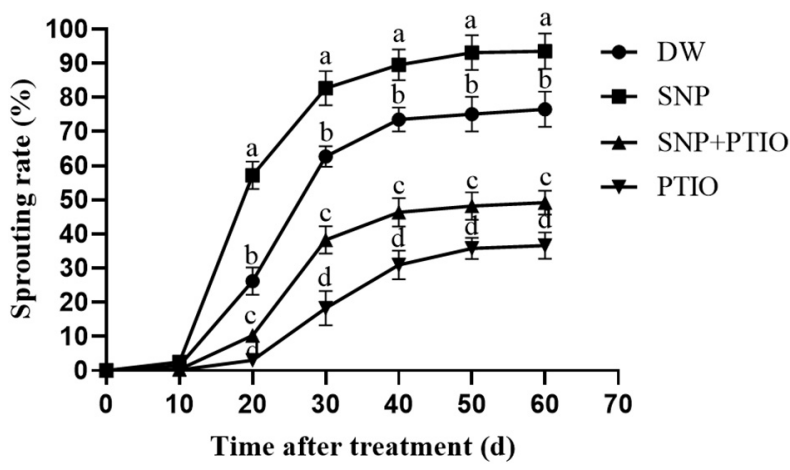

FIGURE 1 | Effects of SNP and C-PTIO on tuber sprouting. (A) Effect of different SNP concentrations on tuber dormancy release. Dormant tubers were sprayed with DW (control) or 10, 20, 40, 80, 160, or $320 \mu \mathrm{M}$ SNP for 15 min. (B) Effect of SNP and the NO scavenger c-PTIO on tuber dormancy and sprouting. Dormant tubers were sprayed with DW (control), $40 \mu \mathrm{M}$ SNP, $1 \mathrm{mM}$ c-PTIO, or $40 \mu \mathrm{M}$ SNP + $1 \mathrm{mM}$ c-PTIO for $15 \mathrm{~min}$. Data are presented as the mean $\pm \mathrm{SD}$ for three replicates. When $p<0.05$, the difference is significant according to Duncan multiple-range test. Values marked with the same letter indicate no significant difference. 


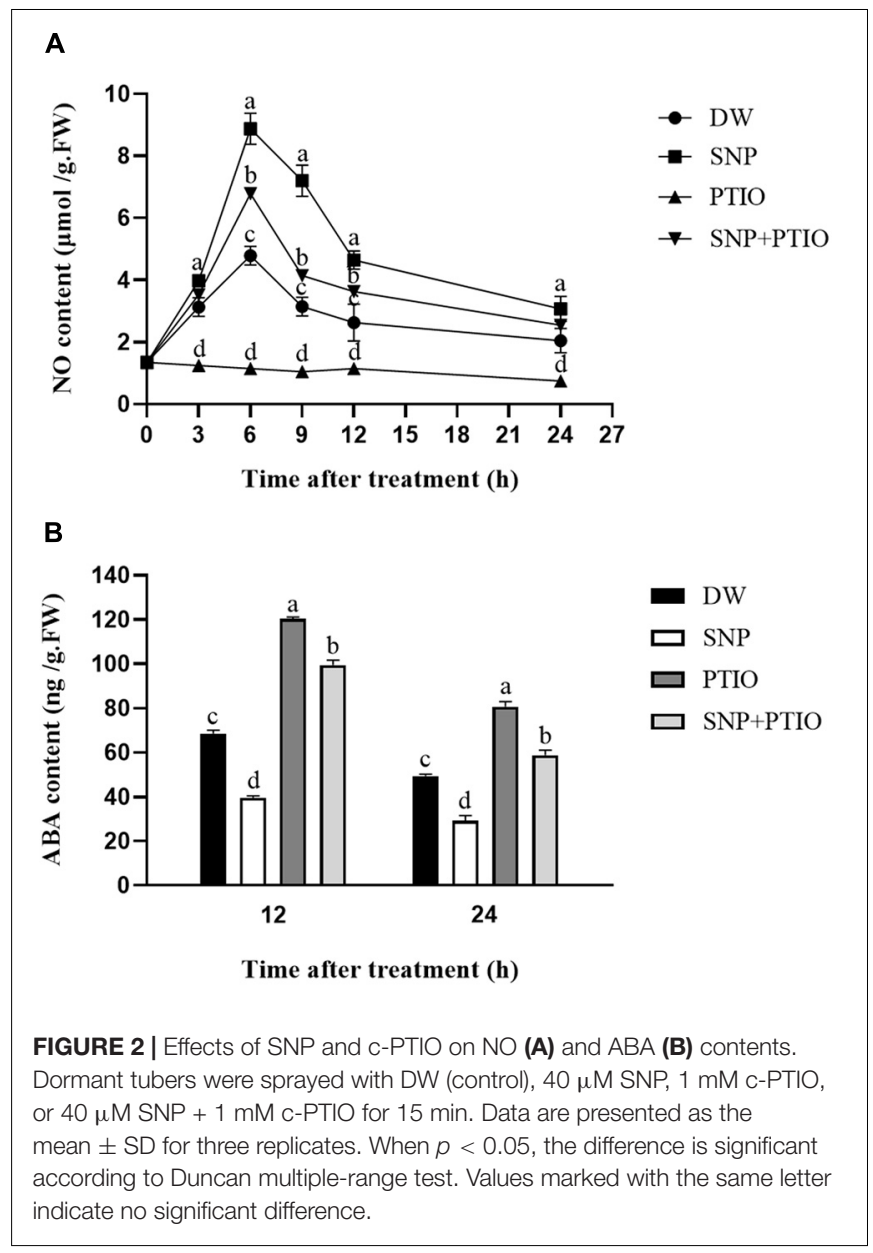

26.22\% (Figure 1B). These results demonstrated that exogenous SNP treatment induced tuber dormancy release and accelerated sprouting. The NO scavenger c-PTIO markedly inhibited tuber sprouting, although combined treatment with both SNP and c-PTIO partially reversed this effect (Figure 1B).

\section{Effects of SNP and c-PTIO on NO and ABA Contents}

The NO and ABA contents were measured after the different treatments. As shown in Figure 2A, compared with the control, SNP treatment led to a rapid increase in the NO content during the first $6 \mathrm{~h}$, which then gradually decreased. Treatment with c-PTIO alone strongly inhibited the increase in NO content, and c-PTIO also partially inhibited the increase in NO content induced by SNP, as shown in Figure 2A. As shown in Figure 2B, compared with the control, SNP treatment decreased the ABA content at 12 and $24 \mathrm{~h}$ after treatment, whereas c-PTIO treatment significantly increased the ABA content.

\section{Influence of Enzyme Inhibitors on Relative Gene Expression}

The relative expression levels of the StNOS-IP (encoding NOSinteracting protein) and StNR (encoding NR) genes after enzyme inhibitor treatment were analyzed via qRT-PCR. As shown in Figure 3A, treatment with L-NAME had little effects on the expression level of StNOS-IP gene. Similarly, the treatment with tungstate had no obvious influence on the expression level of StNR gene (Figure 3B).

To elucidate the role of NO in ABA metabolism in tuber buds, the expression of genes related to ABA metabolism (StCYP707A1, encoding ABA $8^{\prime}$-hydroxylase) and ABA biosynthesis (StNCED1, encoding 9-cis-epoxycarotenoid dioxygenase) was also examined. As shown in Figure 3C, SNP treatment significantly increased the expression of StCYP707A1 compared with the control, and the highest expression occurred in $6 \mathrm{~h}$ after treatment. In contrast, as shown in Figure 3D, SNP treatment significantly decreased the expression of StNCED1 compared with the control. These results demonstrated that $\mathrm{NO}$ promoted the expression of ABA catabolism gene (StCYP707A1) and inhibited the expression of ABA biosynthesis gene (StNCED1).

\section{Influence of Enzyme Inhibitors on NOS-Like and NR Activities}

To investigate the effect of the enzyme inhibitors on enzyme activity, the NOS-like and NR activities were measured. As shown in Figure 4A, L-NAME treatment markedly suppressed the NOSlike activity throughout the 60-day observation period compared with the control, and the highest NOS-like activity was observed at 20 days after treatment. A similar trend was observed for the NR activity after tungstate treatment (Figure 4B).

\section{Influence of NO on ABA Tolerance of Potato During Sprouting}

It is well known that ABA effectively inhibits the sprouting of tubers. As shown in Figure 5, the treatment of dormant tubers with $100 \mu \mathrm{M}$ ABA significantly inhibited sprouting compared with the control. However, upon the addition of $40 \mu \mathrm{M}$ SNP to $\mathrm{ABA}$, the sprouting rate of the tubers was increased, whereas the addition of $1 \mathrm{mM}$ c-PTIO to ABA caused the sprouting rate to further decrease. These results demonstrated that NO increased the ABA tolerance of potato during sprouting.

\section{Influence of ABA Treatment on NO Content}

To examine the effect of ABA on NO, the NO content was measured following ABA treatment. As shown in Figure 6, compared with the control, the NO content was decreased at 3 and $6 \mathrm{~h}$ after ABA treatment. The addition of SNP to ABA partially mitigated this decrease at both time points. These results demonstrated that ABA treatment decreased the NO content in potato during sprouting.

\section{Influence of ABA on Relative Gene Expression}

The effects of ABA on the relative expression of the StNOS$I P$, StNR, StCYP707A1, and StNCED1 genes were analyzed via qRT-PCR. As shown in Figures 7A,B, ABA treatment decreased the relative expression of the StNOS-IP and StNR genes after 12 h compared with the control, whereas ABA + SNP treatment 
A

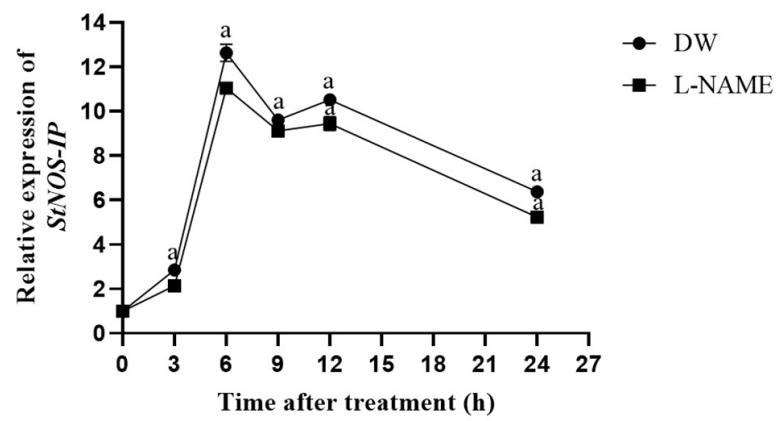

C

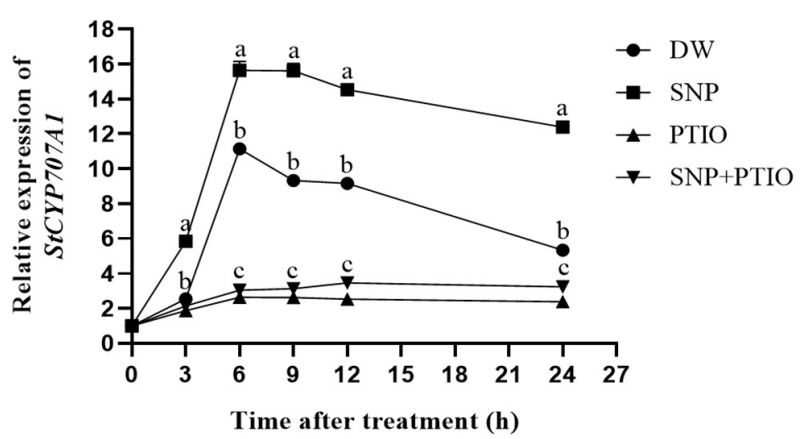

B

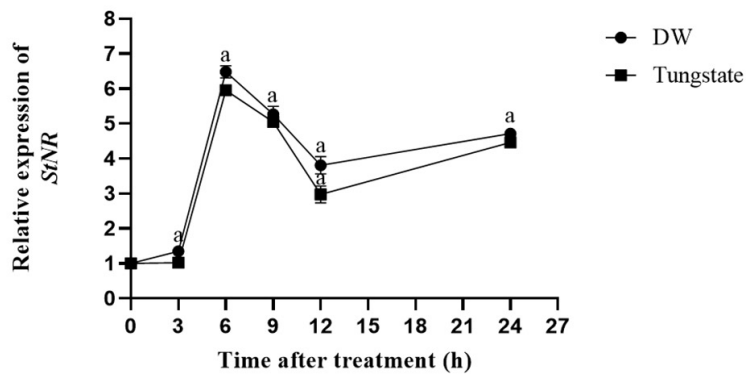

D

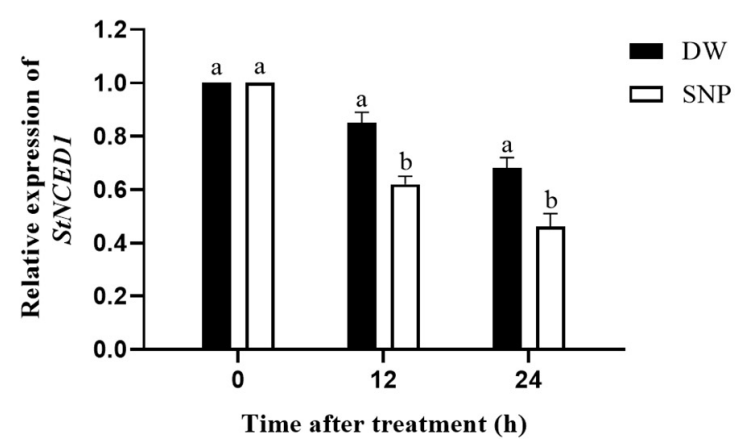

FIGURE 3 | Changes of the relative expression levels of genes (StNOS-IP, StNR, StCYP707A1, and StNCED1). (A) Effect of L-NAME treatment on the expression of StNOS-IP gene. Dormant tubers were sprayed with DW (control) or $1 \mathrm{mM} \mathrm{L-NAME}$ for $15 \mathrm{~min}$. (B) Effect of tungstate treatment on the expression of StNR gene. Dormant tubers were sprayed with DW (control) or $1 \mathrm{mM}$ tungstate for $15 \mathrm{~min}$. (C) Effect of SNP treatment on the expression of StCYP707A1 gene. Dormant tubers were sprayed with DW (control), $40 \mu \mathrm{M}$ SNP, $1 \mathrm{mM}$ c-PTIO, or $40 \mu \mathrm{M}$ SNP + 1 mM c-PTIO for 15 min. (D) Effect of SNP treatment on the expression of StNCED1 gene. Dormant tubers were sprayed with DW (control) or $40 \mu \mathrm{M}$ SNP for $15 \mathrm{~min}$. Data are presented as the mean \pm SD for three replicates. When $p<0.05$, the difference is significant according to Duncan multiple-range test. Values marked with the same letter indicate no significant difference.

partially mitigated this decrease for both genes. As shown in Figures 7C,D, ABA treatment had little effect on the expression level of the StCYP707A1 gene, although it increased the relative expression of StNCED1 gene after $12 \mathrm{~h}$ of treatment compared with the control.

\section{Influence of ABA on NOS-Like and NR Activities}

To investigate the effect of ABA on NO, the NOS-like and NR activities were measured following ABA treatment. As shown in Figure 8, the NOS-like and NR activities decreased at 3 and $6 \mathrm{~h}$ after ABA treatment compared with the control. The addition of SNP to ABA partially reversed this inhibitory effect for both enzymes. These results showed that ABA treatment inhibited the activities of NOS-like and NR in potato during sprouting.

\section{DISCUSSION}

NO has been demonstrated to play a critical role in dormancy breaking or germination in several plants, including wheat (Bethke et al., 2006a; Jacobsen et al., 2013), barley (Bethke et al., 2004), warm-season $C_{4}$ grass (Sarath et al., 2006), and lettuce (Beligni and Lamattina, 2000). Liu et al. (2009) reported that the NO donor SNP broke seed dormancy, whereas the
NO scavenger c-PTIO blocked the effects of NO donors and extended dormancy in Arabidopsis. In this study, the exogenous $40 \mu \mathrm{M}$ SNP treatment quickly broke the dormancy of tubers and promoted their rapid sprouting (Figure 1A), whereas the NO scavenger c-PTIO markedly delayed tuber sprouting (Figure 1B). However, combined treatment with SNP and c-PTIO partially reversed the effect of c-PTIO (Figure 1B). In plant research, the most common $\mathrm{NO}$ donors are SNP, S-nitrosopenicillamine (SNAP), S-nitrosoglutathione (GSNO), and diethylamine NONOate (DETA/NO). Different donors have different mechanisms of NO release. For example, SNP releases the nitrosonium cation $\left(\mathrm{NO}^{+}\right)$, whereas SNAP and GSNO typically release the $\mathrm{NO}$ radical $(\cdot \mathrm{NO})$. In aqueous solution, DETA/NO and SNAP produce instantaneous NO bursts lasting seconds to minutes, whereas the NO release effect of SNP is more prolonged (Planchet and Kaiser, 2006; Mur et al., 2013). SNP is one of the most extensively studied NO donors and can be used for the persistent production of NO (Mur et al., 2013). However, there are some shortcomings with the application of SNP. For example, the release of NO from SNP is accompanied by the production of the toxic gas hydrogen cyanide (Bethke et al., 2006b). According to the report of Oracz et al. (2009), SNP produced cyanide that was likely to induce ROS generation, for instance, hydrogen peroxide $\left(\mathrm{H}_{2} \mathrm{O}_{2}\right)$. Because of time constraints, $\mathrm{H}_{2} \mathrm{O}_{2}$ content could not be measured in time in this study. In 


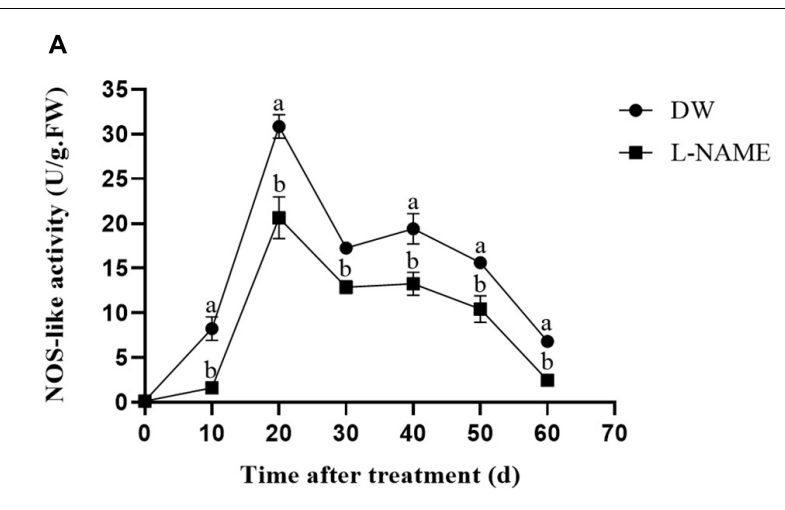

B

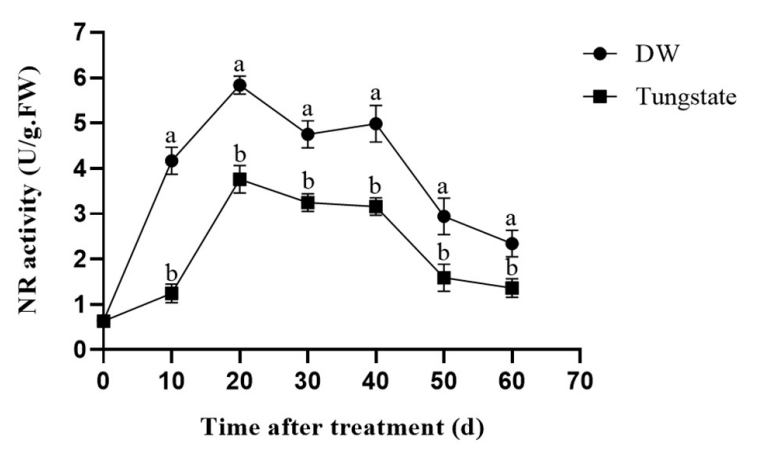

FIGURE 4 | Effect of enzyme inhibitors on NOS-like and NR activities. (A) NOS-like activity in potato tubers. Dormant tubers were sprayed with DW (control) or $1 \mathrm{mM}$ L-NAME for $15 \mathrm{~min}$. (B) NR activity in potato tubers. Dormant tubers were sprayed with DW (control) or $1 \mathrm{mM}$ tungstate for $15 \mathrm{~min}$. Data are presented as the means \pm SD for three replicates. When $p<0.05$, the difference is significant according to Duncan multiple-range test. Values marked with the same letter indicate no significant difference.

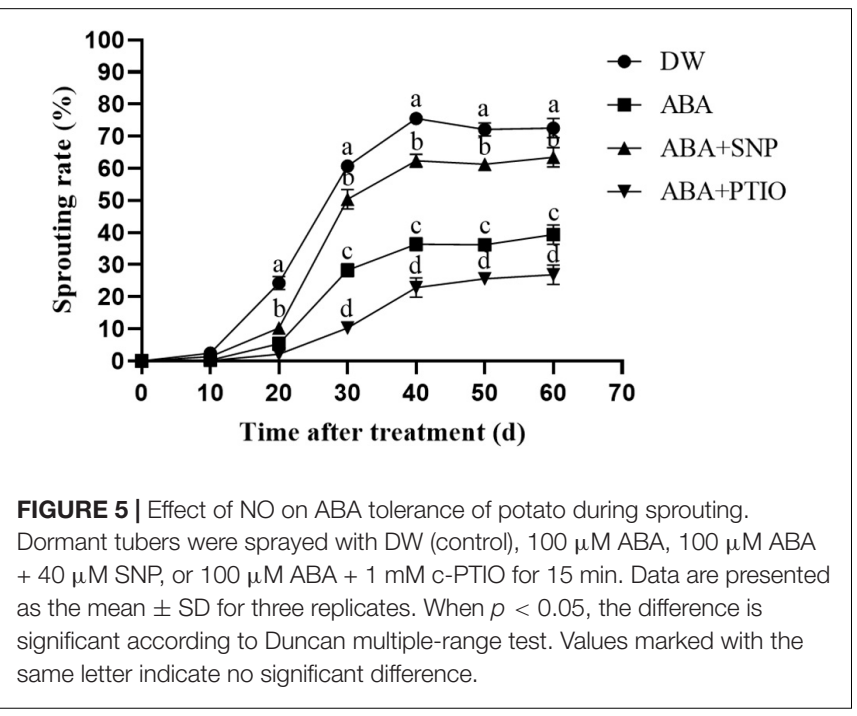

Arabidopsis and barley seed, c-PTIO enhanced their dormancy (Bethke et al., 2004). In short, our findings are consistent with those reports for other species.

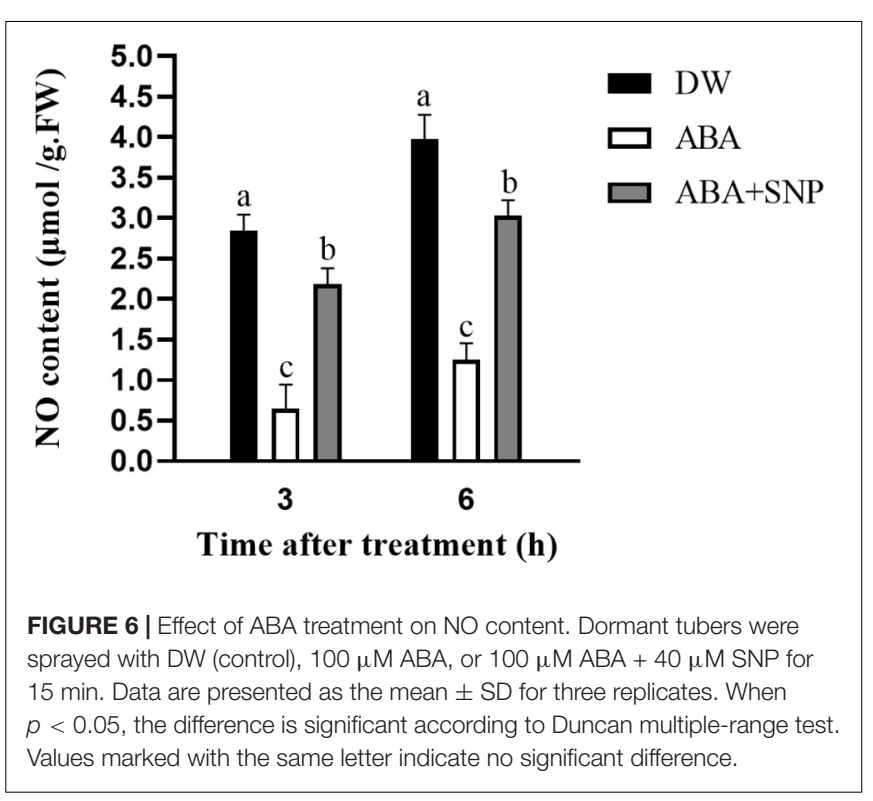

The recent plans to deregister Chlorpropham (CIPC) in European refer to germination inhibitors and herbicide CIPC have been banned use by the Council of Europe since January 1, 2020. The European Commission has published its 2019/989 implementing regulations on the nonextension of the approved active substance CIPC. According to this ordinance, the CIPC authorization has not been renewed. Member states should countermand their authorization for plant protection products involving CIPC as an active substance by January 8, 2020. CIPC is a highly efficient potato bud inhibitor (Frazier and Olsen, 2015). In the past, some export regulations required that potatoes must be treated with CIPC or other bud inhibitors as a plant disease prevention measure. However, CIPC is slightly toxic and remains in the potato tubers after application, which could cause harm to people and the environment (Abbasi et al., 2015). In an effort to effectively inhibit sprouting and reduce the occurrence of diseases during storage, tubers are typically stored at low temperature (Ou et al., 2014). Under the conditions of low-temperature storage, the content of reducing sugars in the tubers rapidly increases (Malone et al., 2006). During hightemperature processing, these reducing sugars react with free amino acids in tubers via the Maillard reaction (Claassen et al., 1993), which severely affects the color of fried tuber strips and flakes. Because the content of reducing sugars in potato chips is negatively correlated with the color of the chips, a higher reducing sugar content leads to decreased quality. The change in reducing sugar content in potato tubers is closely related to the temperature. When the storage temperature of tubers was lower than $10^{\circ} \mathrm{C}$, the reducing sugar content increased, and the sucrose content also increased significantly. At $10^{\circ} \mathrm{C}$, although the reducing sugar content increased slightly, the sucrose content remained essentially unchanged.

Detailed morphological analysis revealed that bud growth was not observed when tubers were dormant after harvest (Van Ittersum et al., 1992). At the molecular level, the 


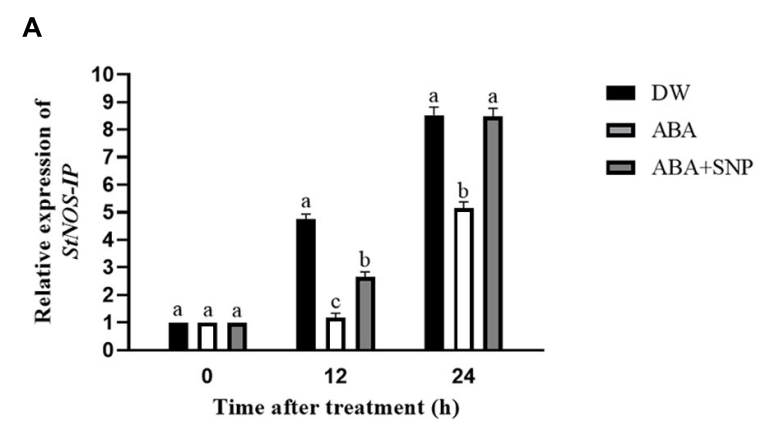

C

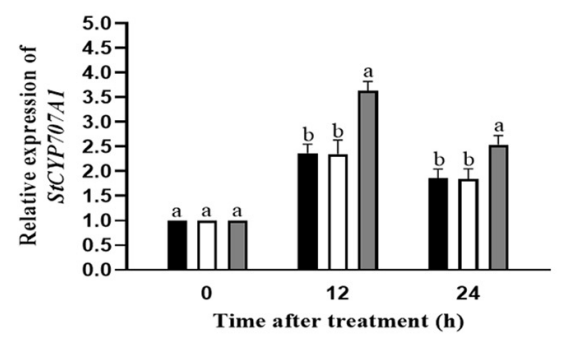

B

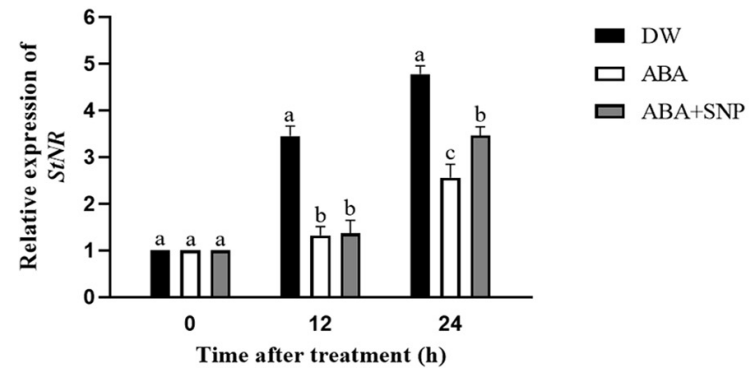

D

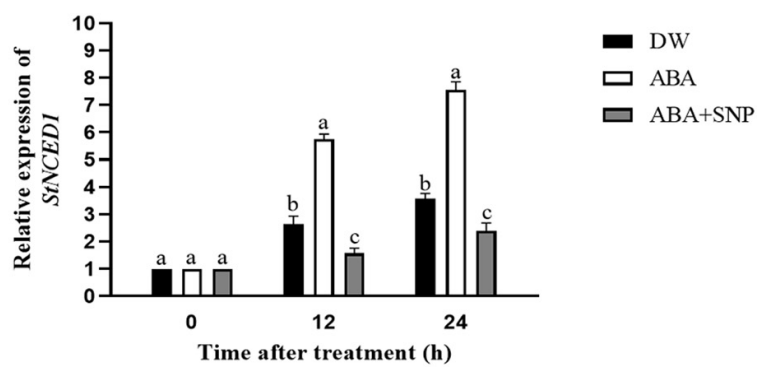

FIGURE 7 | Effect of ABA treatment on the relative expression of genes StNOS-IP (A), StNR (B), StCYP707A1 (C), and StNCED1 (D). Dormant tubers were sprayed with DW (control), $100 \mu \mathrm{M}$ ABA, or $100 \mu \mathrm{M}$ ABA $+40 \mu \mathrm{M}$ SNP for $15 \mathrm{~min}$. Data are presented as the mean \pm SD for three replicates. When $p<0.05$, the difference is significant according to Duncan multiple-range test. Values marked with the same letter indicate no significant difference.

meristem of the dormant tuber bud is rarely divided. When the buds begin to grow after the end of the dormancy (Leshem and Clowes, 1972), the cells in the middle stage of division are also increasing. Although mitosis is in a resting state, the resting meristem still possesses metabolic activity. Numerous studies have demonstrated that dormant meristems capture and incorporate precursors of RNA and proteins.

The NO and ABA contents were measured after the various treatments. Compared with the control, SNP treatment caused a rapid increase in the $\mathrm{NO}$ content at $6 \mathrm{~h}$, which then gradually decreased, whereas c-PTIO treatment strongly inhibited the increase in NO content (Figure 2A). The addition of c-PTIO also partially mitigated the increase in the $\mathrm{NO}$ content caused by SNP (Figure 2B). Liu et al. (2009) reported that the fluorescence intensity was increased at $3 \mathrm{~h}$ before inhibition in Arabidopsis seeds and decreased after $6 \mathrm{~h}$, while the fluorescence intensity was decreased after c-PTIO treatment. However, owing to technical and experimental constraints, we failed to detect $\mathrm{NO}$ using the fluorescent dye DAF-FMDA. The ABA content decreased at 12 and $24 \mathrm{~h}$ after treatment with SNP, whereas c-PTIO treatment significantly increased the ABA content (Figure 2B).

NOS-like and NR activities are two primary enzymatic sources of NO in plants (Parankusam et al., 2017). An increasing number of studies have demonstrated the presence of NOS-like activity in plants and its similarity to the mammalian enzyme (Del Río et al., 2004). Moreover, L-NAME, an NOS inhibitor, inhibits NO production in plants (Zhang et al., 2007), and tungstate, an NR inhibitor, was reported to inhibit NO production in Arabidopsis (Kolbert et al., 2010). To assess the effect of these enzyme inhibitors on enzymatic activity, the NOS-like and NR activities were measured. Compared with the control, L-NAME treatment markedly suppressed the NOS-like activity throughout the duration of the experiment, and the NOS-like activity reached its highest level at 20 days after treatment (Figure 4A). The same trend was observed for the NR activity following tungstate treatment (Figure 4B). Furthermore, the relative expression levels of the StNOS-IP and StNR genes were analyzed via qRTPCR after enzyme inhibitor treatment. The results revealed that L-NAME treatment had no effect on the expression of the StNOS-IP gene (Figure 3A), and tungstate treatment had no effect on the expression of the StNR gene (Figure 3B). The StNOS-IP gene encoding NOS-interacting protein was obtained from the National Center for Biotechnology Information (NCBI) database $^{1}$ and was blasted in the Potato Genome Sequencing Consortium (PGSC) database ${ }^{2}$. The results revealed that this gene was predicted in the NCBI database (LOC102602935), but was a conserved gene of unknown function in the PGSC database (PGSC0003DMT400057534). We downloaded the sequence of this gene from the NCBI database and designed qRT-PCR primers. The gene possessed a total length of $1234 \mathrm{bp}$, a coding sequence length of $915 \mathrm{bp}$, and a translated protein length of 304 amino acids and contained two exons. However, the expression of the StNOS-IP gene had effect on the activity of NOS-like. How this gene influences the enzyme activity is unclear and will need further study.

\footnotetext{
${ }^{1}$ https://www.ncbi.nlm.nih.gov

${ }^{2} \mathrm{http} / / /$ solanaceae.plantbiology.msu.edu/pgsc_download.shtml
} 


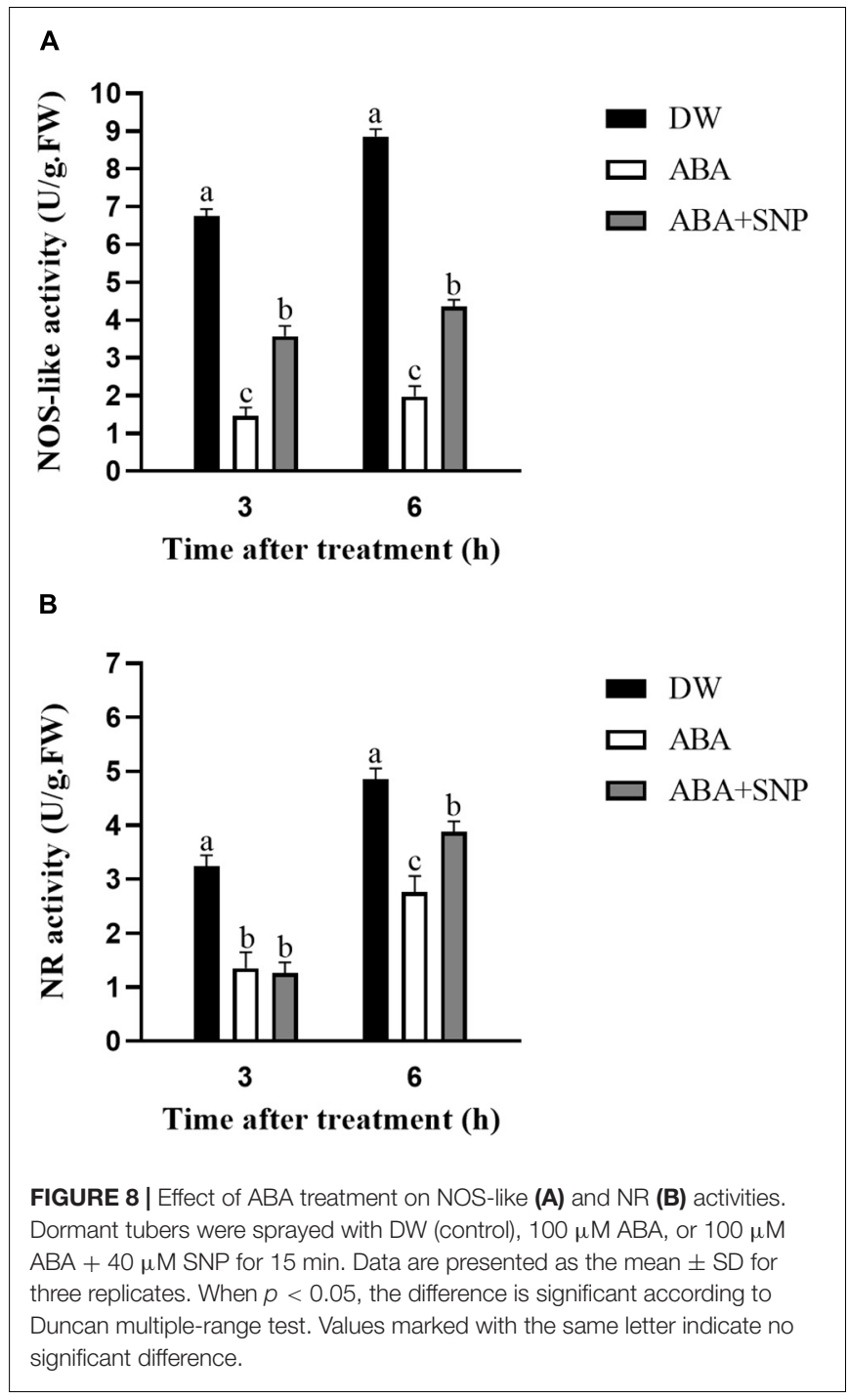

It has been suggested that $\mathrm{NO}$ is involved in mediating $\mathrm{ABA}$ catabolism. The CYP707A families of genes, which encode ABA $8^{\prime}$-hydroxylases, are responsible for regulating ABA catabolism (Sanz et al., 2015). The mechanism underlying the effect of NO on potato tuber dormancy remains unclear at present. To elucidate the role of $\mathrm{NO}$ in ABA metabolism in tuber buds, the expression of genes involved in ABA catabolism (StCYP707A1) and ABA biosynthesis (StNCED1) was also examined. The expression of StCYP707A1 after SNP treatment was significantly higher than that in the control, and the highest expression occurred at $6 \mathrm{~h}$ after treatment (Figure 3C). In contrast, the expression of StNCED1after SNP treatment was significantly lower than that in the control (Figure 3D). These results demonstrated that NO promoted the expression of StCYP707A1 and inhibited the expression of StNCED1.

It is well known that ABA inhibits seed germination. At present, it is generally believed that $\mathrm{ABA}$ is a positive regulator of dormancy induction, which is involved in the maintenance of dormancy and the decrease of endogenous ABA content

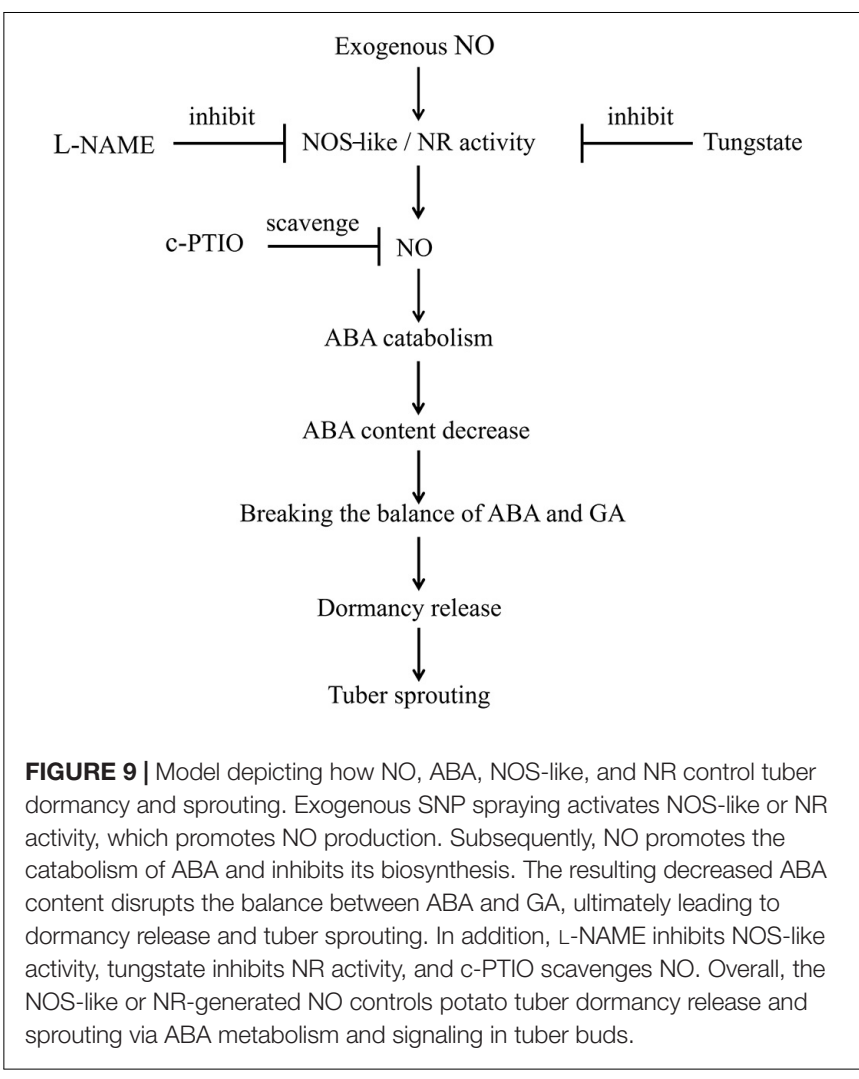

during the release of dormancy (Campbell et al., 2008; Suttle et al., 2012). The use of the ABA inhibitors and the discovery of a synthetic mutant of ABA confirmed that ABA inhibits the release of dormancy, although this inhibitory effect can be reversed by GA. The crosstalk between ABA and NO regulating dormancy and germination in seed has been reported. Used exogenous SNP, an NO donor, promote NO production, which inhibits $\mathrm{ABA}$ synthesis and promotes ABA catabolism. According to the report of ABA crosstalk with ethylene and $\mathrm{NO}$ in seed dormancy and germination (Arc et al., 2013b), the signal transduction between $\mathrm{ABA}$ and $\mathrm{NO}$ was realized by PYR/PYL/RCAR receptor (Staszak et al., 2017). When ABA does not combine with the receptor, $2 \mathrm{C}$ protein phosphatase (PP2C) dephosphorylates sucrose nonfermenting 1-related protein kinase 2 (SnRK2) (Manohar et al., 2017). When ABA combining with the receptor, induces the formation of a protein complex with PP2C (Staszak et al., 2017) and releases inhibition of SnRK2 activity, which can phosphorylate downstream targets, containing ABA insensitive 5 (ABI5)-related transcription factors (Lim et al., 2015). Interactions between ABI3 and ABI5 mediate transcriptional regulation of ABA-responsive genes (Arc et al., 2013b). In our study, we suppose that treatment with exogenous SNP, an NO donor, activates NOS-like or NR activity, thereby promoting NO production. Subsequently, NO promotes the catabolism of ABA and inhibits its biosynthesis. Therefore, the ABA content is decreased, disrupting the balance between ABA and GA. Finally, dormancy release and tuber sprouting occur. However, the specific molecular mechanism of $\mathrm{NO}$ and ABA 
interaction regulating the dormancy and sprouting of potato tubers remains unclear and will need further study.

The cotreatment of seeds with $200 \mu \mathrm{M}$ SNP and $10 \mu \mathrm{M}$ ABA was reported to promote the embryo root growth after 4 days, compared with treatment with ABA alone (Sarath et al., 2006). In addition, NO effectively improved the tolerance of Arabidopsis seeds to ABA (Liu et al., 2009). In our study, treatment of dormant tubers with $100 \mu \mathrm{M}$ ABA significantly inhibited tuber sprouting compared with the control (Figure 5). However, upon adding $40 \mu \mathrm{M}$ SNP to ABA, the sprouting rate of the tubers increased, and upon adding $1 \mathrm{mM}$ c-PTIO to ABA, the sprouting rate of the tubers further decreased. These results demonstrated that NO improved the ABA tolerance of potato during sprouting.

To study the influence of ABA on NO, the NO content was measured following ABA treatment. As shown in Figure 6, compared with the control, the NO content decreased at 3 and $6 \mathrm{~h}$ after ABA treatment. The addition of SNP to ABA partially reversed this decrease at both time points. These results indicated that $\mathrm{ABA}$ treatment decreased the NO content in potato during sprouting. The NOS-like and NR activities were also measured following ABA treatment. Both activities decreased at 3 and $6 \mathrm{~h}$ after ABA treatment compared with the control, and the addition of SNP to ABA reversed the inhibitory effect of ABA on the activities of these two enzymes (Figure 8). These results showed that ABA treatment inhibited both the NOS-like and NR activities in potato tuber during sprouting.

The effects of ABA on the relative expression levels of the StNOS-IP, StNR, StCYP707A1, and StNCED1 genes were analyzed by qRT-PCR. ABA decreased the relative expression of the StNOS-IP and StNR genes after $12 \mathrm{~h}$ of treatment (Figures 7A,B) compared with the control, whereas ABA + SNP treatment partially mitigated this decrease for both genes. ABA treatment had little influence on the expression level of the StCYP707A1 gene, although it increased that of StNCED1

\section{REFERENCES}

Abbasi, K. S., Masud, T., Ali, S., Khan, S. U., Mahmood, T., and Qayyum, A. (2015). Sugar-starch metabolism and antioxidant potential in potato tubers in response to different antisprouting agents during storage. Potato Res. 58, 361-375. doi: 10.1007/s11540-015-9306-4

Aksenova, N. P., Sergeeva, L. I., Konstantinova, T. N., Golyanovskaya, S. A., Kolachevskaya, O. O., and Romanov, G. A. (2013). Regulation of potato tuber dormancy and sprouting. Russ. J. Plant Physiol. 60, 301-312. doi: 10.1134/ S1021443713030023

Arc, E., Galland, M., Godin, B., Cueff, G., and Rajjou, L. (2013a). Nitric oxide implication in the control of seed dormancy and germination. Front. Plant Sci. 4:346. doi: 10.3389/fpls.2013.00346

Arc, E., Sechet, J., Corbineau, F., Rajjou, L., and Marion-Poll, A. (2013b). ABA crosstalk with ethylene and nitric oxide in seed dormancy and germination. Front. Plant Sci. 4:63. doi: 10.3389/fpls.2013.00063

Begara-Morales, J. C., Chaki, M., Valderrama, R., Mata-Pérez, C., Padilla, M. N., and Barroso, J. B. (2019). The function of S-nitrosothiols during abiotic stress in plants. J. Exp. Bot. 70, 4429-4439. doi: 10.1093/jxb/erz197

Begara-Morales, J. C., Chaki, M., Valderrama, R., Sánchez-Calvo, B., Mata-Pérez, C., Padilla, M. N., et al. (2018). Nitric oxide buffering and conditional nitric gene after $12 \mathrm{~h}$ of treatment compared with the control (Figures 7C,D).

In summary, treatment with exogenous SNP, an NO donor, activates NOS-like or NR activity, thereby promoting NO production. Subsequently, NO promotes the catabolism of ABA and inhibits its biosynthesis. Therefore, the ABA content is decreased, disrupting the balance between ABA and GA. Finally, dormancy release and tuber sprouting occur. In addition, L-NAME and tungstate inhibit the activities of NOS-like and NR, respectively, and c-PTIO scavenges NO. Ultimately, the NOSlike or NR-generated NO controls potato tuber dormancy release and sprouting via ABA metabolism and signaling in tuber buds (Figure 9). However, the interactions between NO, GA, and ABA during the tuber dormancy release process are highly complex, and the underlying mechanisms require further study.

\section{DATA AVAILABILITY STATEMENT}

The datasets generated for this study are available on request to the corresponding author.

\section{AUTHOR CONTRIBUTIONS}

$\mathrm{NZ}$ and HS conceived and designed the experiments. ZW, RM, $\mathrm{MZ}$, and FW performed the laboratory experiments. ZW, MZ, and FW performed the data analysis and interpretation. ZW, NZ, and HS wrote the manuscript.

\section{FUNDING}

The National Natural Science Foundation of China (No. 31560413) and the Potato Industry Technology System of Gansu Province (GARS-03-P1) supported this research. oxide release in stress response. J. Exp. Bot. 69, 3425-3438. doi: 10.1093/jxb/ ery072

Beligni, M. V., and Lamattina, L. (2000). Nitric oxide stimulates seed germination and de-etiolation, and inhibits hypocotyls elongation, three light-inducible responses in plants. Planta 210, 215-221. doi: 10.1007/PL00008128

Bethke, P. C., Gubler, F., Jacobsen, J. V., and Jones, R. L. (2004). Dormancy of Arabidopsis seeds and barley grains can be broken by nitric oxide. Planta 219, 847-855. doi: 10.1007/s00425-004-1282-x

Bethke, P. C., Libourel, I. G. L., and Jones, R. L. (2006a). Nitric oxide reduces seed dormancy in Arabidopsis. J. Exp. Bot. 57, 517-526. doi: 10.1093/jxb/erj060

Bethke, P. C., Libourel, I. G., Reinohl, V., and Jones, R. L. (2006b). Sodium nitroprusside, cyanide, nitrite, and nitrate break Arabidopsis seed dormancy in a nitric oxide-dependent manner. Planta 223, 805-812. doi: 10.2307/2338 9285

Campbell, M., Segear, E., Beers, L., Knauber, D., and Suttle, J. (2008). Dormancy in potato tuber meristems: chemically induced cessation in dormancy matches the natural process based on transcript profiles. Funct. Integr. Genom. 8, 317-328. doi: 10.1007/s10142-008-0079-6

Chamizo-Ampudia, A., Sanz-Luque, E., Llamas, A., Galvan, A., and Fernandez, E. (2017). Nitrate reductase regulates plant nitric oxide homeostasis. Trends Plant Sci. 22, 163-174. doi: 10.1016/j.tplants.2016.12.001 
Claassen, P. A. M., Budde, M. A. W., and Calker, M. H. V. (1993). Increase in phophorylase activity during cold-induced sugar accumulation in potato tubers. Potato Res. 36, 205-217. doi: 10.1007/BF02360529

Del Río, L. A., Corpas, F. J., and Barroso, J. B. (2004). Nitric oxide and nitric oxide synthase activity in plants. Phytochemistry 65, 783-792. doi: 10.1016/j. phytochem.2004.02.001

Diao, Q., Song, Y., Shi, D., and Qi, H. (2017). Interaction of polyamines, abscisic acid, nitric oxide, and hydrogen peroxide under chilling stress in tomato (Lycopersicon esculentum Mill.) seedlings. Front. Plant Sci. 8:203. doi: 10.3389/ fpls.2017.00203

Frazier, M. J., and Olsen, N. L. (2015). The effects of chlorpropham exposure on field-grown potatoes. Am. J. Potato Res. 92, 32-37. doi: 10.1007/s12230-0149408-6

Gupta, K. J., Fernie, A. R., Kaiser, W. M., and van Dongen, J. T. (2011). On theorigins of nitric oxide. Trends Plant Sci. 16, 160-168. doi: 10.1016/j.tplants. 2010.11.007

Hasanuzzaman, M., Oku, H., Nahar, K., Bhuyan, M. H. M. B., Mahmud, J. A., Baluska, F., et al. (2018). Nitric oxide-induced salt stress tolerance in plants: ROS metabolism, signaling, and molecular interactions. Plant Biotechnol. Rep. 12, 77-92. doi: 10.1007/s11816-018-0480-0

Jacobsen, J. V., Barrero, J. M., Hughes, T., Julkowska, M. M., Taylor, J. M., Xu, Q., et al. (2013). Roles for blue light, jasmonate and nitric oxide in the regulation of dormancy and germination in wheat grain (Triticum aestivum L.). Planta 238, 121-138. doi: 10.1007/s00425-013-1878-0

Khurana, A., Khurana, J. P., and Babbar, S. B. (2011). Nitric oxide induces flowering in the duckweed Lemna aequinoctialis Welw. (Syn. L. paucicostata Hegelm.) under noninductive conditions. J. Plant Growth Regul. 30, 378-385. doi: 10. 1007/s00344-011-9199-7

Kolbert, Z., Ortega, L., and Erdei, L. (2010). Involvement of nitrate reductase (NR) in osmotic stress-induced NO generation of Arabidopsis thaliana L. roots. J. Plant Physiol. 167, 77-80. doi: 10.1016/j.jplph.2009.08.013

Koornneef, M., Bentsink, L., and Hilhorst, H. (2002). Seed dormancy and germination. Curr. Opin. Plant Biol. 5, 33-36. doi: 10.1016/S1369-5266(01) 00219-9

Kundu, A., Patel, A., and Pal, A. (2013). Defining reference genes for qPCR normalization to study biotic and abiotic stress responses in Vigna mungo. Plant Cell Repot 32, 1647-1658. doi: 10.1007/s00299-013-1478-2

Leshem, B., and Clowes, F. A. L. (1972). Rates of mitosis in shoot apices of potatoes at the beginning and end of dormancy. Ann. Bot. 36, 687-691. doi: 10.1093/ oxfordjournals.aob.a084624

Lim, C., Baek, W., Jung, J., Kim, J.-H., and Lee, S. (2015). Function of ABA in stomatal defense against biotic and drought stresses. Int. J. Mol. Sci. 16, 15251-15270. doi: 10.3390/ijms160715251

Liu, B. L., Zhang, N., Wen, Y. K., Jin, X., Yang, J. W., Si, H. J., et al. (2015). Transcriptomic changes during tuber dormancy release process revealed by RNA sequencing in potato. J. Biotechnol. 198, 17-30. doi: 10.1016/j.jbiotec.2015. 01.019

Liu, Y. G., Shi, L., Ye, N. H., Liu, R., Jia, W. S., and Zhang, J. H. (2009). Nitric oxideinduced rapid decrease of abscisic acid concentration is required in breaking seed dormancy in Arabidopsis. New Phytol. 183, 1030-1042. doi: 10.1111/j. 1469-8137.2009.02899.x

Liu, Y. G., Ye, N. H., Liu, R., Chen, M. X., and Zhang, J. H. (2010). $\mathrm{H}_{2} \mathrm{O}_{2}$ mediates the regulation of ABA catabolism and GA biosynthesis in Arabidopsis seed dormancy and germination. J. Exp. Bot. 61, 2979-2990. doi: 10.1093/jxb/erq125

Livak, K. J., and Schmittgen, T. D. (2001). Analysis of relative gene expression data using real-time quantitative PCR and the $2^{-\Delta \Delta C_{\mathrm{T}}}$ method. Methods 25, 402-408. doi: 10.1006/meth.2001.1262

Lu, S. Y., Zhuo, C. L., Wang, X. H., and Guo, Z. F. (2014). Nitrate reductase (NR)dependent NO production mediates ABA- and $\mathrm{H}_{2} \mathrm{O}_{2}$-induced antioxidant enzymes. Plant Physiol. Biochem. 74, 9-15. doi: 10.1016/j.plaphy.2013. 10.030

Ma, W., Xu, W., Xu, H., Chen, Y., He, Z., and Ma, M. (2010). Nitric oxide modulates cadmium influx during cadmium-induced programmed cell death in tobacco BY-2 cells. Planta 232, 325-335. doi: 10.1007/s00425-010-1177-y

Malone, J. G., Mittova, V., Ratcliffe, R. G., and Kruger, N. J. (2006). The response of carbohydrate metabolism in potato tubers to low temperature. Plant Cell Physiol. 47, 1309-1322. doi: 10.1093/pcp/pcj101
Manohar, M., Wang, D., Manosalva, P. M., Choi, H. W., Kombrink, E., and Klessig, D. F. (2017). Members of the abscisic acid co-receptor PP2C protein family mediate salicylic acid-abscisic acid crosstalk. Plant Direct 1, 1-14. doi: 10.1002/ pld3.20

Mur, L. A., Mandon, J., Persijn, S., Cristescu, S. M., Moshkov, I. E., Novikova, G. V., et al. (2013). Nitric oxide in plants: an assessment of the current state of knowledge. AoB Plants 5:s052. doi: 10.1093/aobpla/pls052

Noritake, T., Kawakita, K., and Doke, N. (1996). Nitric oxide induces phytoalexin accumulation in potato tuber tissues. Plant Cell Physiol. 37, 113-116. doi: 10. 1093/oxfordjournals.pcp.a028908

Oracz, K., El-Maarouf-Bouteau, H., Kranner, I., Bogatek, R., Corbineau, F., and Bailly, C. (2009). The mechanisms involved in seed dormancy alleviation by hydrogen cyanide unravel the role of reactive oxygen species as key factors of cellular signaling during germination. Plant Physiol. 150, 494-505. doi: 10.1104/ pp.109.138107

Ou, Y. B., Liu, X., Xie, C. H., Zhang, H. L., Lin, Y., Li, M., et al. (2014). Genome-wide identification of microRNAs and their targets in cold-stored potato tubers by deep sequencing and degradome analysis. Plant Mol. Biol. Repor. 33, 584-597. doi: 10.1007/s11105-014-0771-8

Parankusam, S., Adimulam, S. S., Bhatnagar-Mathur, P., and Sharma, K. K. (2017). Nitric oxide (NO) in plant heat stress tolerance: current knowledge and perspectives. Front. Plant Sci. 8:1582. doi: 10.3389/fpls.2017.01582

Peivastegan, B., Hadizadeh, I., Nykyri, J., Nielsen, K. L., Somervuo, P., Sipari, N., et al. (2019). Effect of wet storage conditions on potato tuber transcriptome, phytohormones and growth. BMC Plant Biol. 19:262. doi: 10.1186/s12870-0191875-y

Planchet, E., and Kaiser, W. M. (2006). Nitric oxide production in plants: facts and fictions. Plant Signal. Behav. 1, 46-51. doi: 10.4161/psb.1.2.2435

Sanz, L., Albertos, P., Mateos, I., Sánchez-Vicente, I., Lechón, T., FernándezMarcos, M., et al. (2015). Nitric oxide (NO) and phytohormones crosstalk during early plant development. J. Exp. Bot. 66, 2857-2868. doi: 10.1093/jxb/ erv213

Sarath, G., Bethke, P. C., Jones, R., Baird, L. M., Hou, G., and Mitchell, R. B. (2006). Nitric oxide accelerates seed germination in warm-season grasses. Planta 223, 1154-1164. doi: 10.2307/23389359

Sonnewald, S., and Sonnewald, U. (2014). Regulation of potato tuber sprouting. Planta 239, 27-38. doi: 10.1007/s00425-013-1968-z

Srinivas, P., Wink, D., Mohanakumar, K. P., and Pillai, M. R. (2014). The legacy of nitric oxide: impact on disease biology. Nitric Oxide 43, 1-2. doi: 10.1016/j.niox. 2014.09.005

Staszak, A. M., Guzicka, M., and Pawłowski, T. A. (2017). Signaling regulators of abscisic and gibberellic acid pathways are involved in dormancy breaking of Norway maple (Acer platanoides L.) seeds. Acta Physiol. Plant. 39, 241-251. doi: 10.1007/s11738-017-2544-0

Stuehr, D. J., Santolini, J., Wang, Z. Q., Wei, C. C., and Adak, S. (2004). Update on mechanism and catalytic regulation in the NO synthases. J. Biol. Chem. 279, 36167-36170. doi: 10.1074/jbc.R400017200

Sun, A. Z. (2018). The EPR method for detecting nitric oxide in plant senescence. Methods Mol. Biol. 1744, 119-124. doi: 10.1007/978-1-4939-7672-0_10

Sun, H. W., Feng, F., Liu, J., and Zhao, Q. Z. (2018). Nitric oxide affects rice root growth by regulating auxin transport under nitrate supply. Front. Plant Sci. 9:659. doi: 10.3389/fpls.2018.00659

Suttle, J. C., Abrams, S. R., Stefano-Beltrán, L. D., and Huckle, L. L. (2012). Chemical inhibition of potato ABA- $8^{\prime}$-hydroxylase activity alters in vitro and in vivo ABA metabolism and endogenous $\mathrm{ABA}$ levels but does not affect potato microtuber dormancy duration. J. Exp. Bot. 63, 5717-5725. doi: 10.1093/jxb/ ers 146

Teper-Bamnolker, P., Buskila, Y., Lopesco, Y., et al. (2012). Release of apical dominance in potato tuber is accompanied by programmed cell death in the apical bud meristem. Plant Physiol. 158, 2053-2067. doi: 10.1104/pp.112.194076 Van Ittersum, M. K., Aben, F. C. B., and Keijzer, C. J. (1992). Morphological changes in tuber buds during dormancy and initial sprout growth of seed potatoes. Potato Res. 35, 249-260. doi: 10.1007/BF02357705

Wang, H., Huang, J., Li, Y., Li, C., Hou, J., and Liang, W. (2016). Involvement of nitric oxide-mediated alternative pathway in tolerance of wheat to drought stress by optimizing photo synthesis. Plant Cell Rep. 35, 2033-2044. doi: 10. 1007/s00299-016-2014-y 
Wróbel, S., Kȩsy, J., and Treder, K. (2017). Effect of growth regulators and ethanol on termination of dormancy in potato tubers. Am. J. Potato Res. 94, 544-555. doi: 10.1007/s12230-017-9592-2

Zhang, A. Y., Jiang, M. Y., Zhang, J. H., Tan, M. P., and Hu, X. L. (2007). Nitric oxide induced by hydrogen peroxide mediates abscisic acid-induced activation of the mitogen-activated protein kinase cascade involved in antioxidant defense in maize leaves. New Phytol. 175, 35-60. doi: 10.2307/4641022

Zhang, L. S., Shi, X., Zhang, Y. T., Wang, J. J., Yang, J. W., et al. (2019). CLE9 peptide-induced stomatal closure is mediated by abscisic acid, hydrogen peroxide, and nitric oxide in Arabidopsis thaliana. Plant Cell Environ. 42, 1033-1044. doi: 10.1111/pce.13475

Zhang, Y., Tan, J., Guo, Z., Lu, S., Shu, W., and Zhou, B. (2009). Increased ABA levels in transgenic tobacco over-expressing 9-cis-epoxycarotenoid dioxygenase influences $\mathrm{H}_{2} \mathrm{O}_{2}$ and $\mathrm{NO}$ production and antioxidant defenses. Plant Cell Environ. 32, 509-519. doi: 10.1111/j.1365-3040.2009.01945.x

Conflict of Interest: The authors declare that the research was conducted in the absence of any commercial or financial relationships that could be construed as a potential conflict of interest.

Copyright (c) 2020 Wang, Ma, Zhao, Wang, Zhang and Si. This is an open-access article distributed under the terms of the Creative Commons Attribution License (CC BY). The use, distribution or reproduction in other forums is permitted, provided the original author(s) and the copyright owner(s) are credited and that the original publication in this journal is cited, in accordance with accepted academic practice. No use, distribution or reproduction is permitted which does not comply with these terms. 